\title{
Overexpression of $\mathrm{B} 7-\mathrm{H} 4$ promotes renal cell carcinoma progression by recruiting tumor-associated neutrophils via upregulation of CXCL8
}

\author{
ANQI LI ${ }^{*}$, NINGYUE ZHANG ${ }^{1 *}$, ZHIMING ZHAO ${ }^{1}$, YALI CHEN $^{1}$ and LIANG ZHANG ${ }^{1-4}$ \\ ${ }^{1}$ Department of Biological Pharmacy, College of Pharmaceutical Sciences, Soochow University, Suzhou, Jiangsu 215123; \\ ${ }^{2}$ Jiangsu Institute of Clinical Immunology, The First Affiliated Hospital of Soochow University; \\ ${ }^{3}$ Jiangsu Key Laboratory of Clinical Immunology, Soochow University; \\ ${ }^{4}$ Jiangsu Key Laboratory of Gastrointestinal Tumor Immunology, Soochow University, Suzhou, Jiangsu 215006, P.R. China
}

Received March 5, 2019; Accepted November 27, 2019

DOI: $10.3892 / \mathrm{ol} .2020 .11701$

\begin{abstract}
The immune checkpoint molecule B7 family member H4 (B7-H4) plays a similar role to programmed death-ligand 1 in tumor immune evasion by regulating T-cell-mediated immune responses. However, besides the role in T-cell immunity, B7-H4 also affects tumor cell biology by promoting tumor cell proliferation, metastasis and angiogenesis. In order to explore the effect of B7-H4 on tumor cell biology, it is necessary to investigate the gene expression profile when $\mathrm{B} 7-\mathrm{H} 4$ is overexpressed. In the present study, 786-O cells were transfected to stably express B7-H4. A microarray technique was subsequently used to screen B7-H4-related differentially expressed genes (DEGs) in B7-H4/786-O cells compared with negative control (NC)/786-O cells. The protein expression of the upregulated DEGs, including non-metastatic cells 5, NME/NM23 family member 5 (NME5), membrane metalloendopeptidase (MME), vascular non-inflammatory molecule 1 (VNN1), matrix metalloproteinase (MMP) 7, tumor necrosis factor, C-X-C motif chemokine ligand (CXCL) 8, CXCL1 and C-C motif chemokine ligand (CCL) 2, was investigated using western blotting. Kidney renal papillary cell carcinoma mRNA-sequencing data obtained from The Cancer Genome Atlas revealed that chemokines, including CXCL1/2/3, CXCL8, MMP7 and CCL20, were positively correlated with B7-H4 gene expression. Furthermore, 59 clinical renal cell carcinoma tissues were collected and analyzed by immu-
\end{abstract}

Correspondence to: Dr Liang Zhang, Department of Biological Pharmacy, College of Pharmaceutical Sciences, Soochow University, 199 Ren-ai Road, Suzhou, Jiangsu 215123, P.R. China

E-mail: zliang@suda.edu.cn

*Contributed equally

Key words: B7 family member H4, microarray, The Cancer Genome Atlas, C-X-C motif chemokine ligand 8, tumor-infiltrated neutrophils nohistochemical staining. The results revealed the positive correlation of B7-H4 with CCL20 and CXCL8, and validated the DEGs identified in tumor cell lines. 786-O transfectants were inoculated into non-obese diabetic/severe combined immunodeficiency mice, and tumor growth was investigated. B7-H4 overexpression promoted tumor growth and administration of anti-CXCL8 antibody reversed this effect. Furthermore, B7-H4 overexpression increased the number of tumor-infiltrating neutrophils while inhibition of CXCL8 abrogated this effect. These data indicated that recruitment of neutrophils in the tumor microenvironment by CXCL8 serves an important role in the tumor promotion effect of B7-H4. The present study revealed a novel mechanism of $\mathrm{B} 7-\mathrm{H} 4$ in tumor promotion in addition to $\mathrm{T}$ cell inhibition.

\section{Introduction}

Renal cell carcinoma ( RCC) is one of the most common cancers, accounting for $>140,000$ deaths worldwide each year (1). RCC has been considered to be an immunogenic tumor (2). Interleukin-2, interferon $\alpha$ and immune checkpoint inhibitors have been used clinically in RCC therapy (3-5). Novel immunotherapies, such as the combination of anti-programmed death ligand-1 antibody and anti-cytotoxic T-lymphocyte-associated protein 4 antibody, have demonstrated clinical benefit (6). However, only a proportion of patients with RCC benefit from the novel immunotherapies (7). The immune suppression microenvironment of $\mathrm{RCC}$ remains to be investigated.

B7 family member H4 (B7-H4), also known as B7x or $\mathrm{B} 7 \mathrm{~S} 1$, is one of the members of the B7 superfamily of co-stimulatory molecules and serves as an inhibitory modulator of the T-cell response (8). B7-H4 mRNA is widely expressed in human peripheral tissues, but its protein expression in normal tissues seems to be limited (9). To date, B7-H4 has been detected in several types of human cancer tissue. In ovarian cancer, B7-H4 expression is associated with tumor-infiltrated antigen-presenting cells (APCs) (10). In colorectal carcinoma, B7-H4 facilitates tumor proliferation and metastasis (11). The expression of B7-H4 in lung cancer is associated with decreased PFS under nivolumab treatment (12). Elevated 
B7-H4 in breast cancer is associated with an 'immune-cold' microenvironment (13). In renal cell carcinoma, intrahepatic cholangiocarcinoma and thyroid cancer, the expression level of B7-H4 is positively associated with tumor progression (14-16). Previous studies have reported that B7-H4, which is a type I transmembrane glycoprotein, binds to its corresponding receptor on lymphocytes, thus negatively regulating the immune response $(8,17,18)$. However, certain tumors express B7-H4 protein in intracellular compartments (19-22). Unlike tumor-associated macrophages, B-cells and dendritic cells (DCs) with membrane expression of B7-H4, tumor cells expressing intracellular B7-H4 do not inhibit T-cell immunity (21). Therefore, it appears that intracellular B7-H4 has a distinct biological function to membrane-located B7-H4 $(22,23)$. In order to investigate the biological function of B7-H4 in kidney cancer cells, the present study constructed negative control ( $\mathrm{NC}$ /786-O and B7-H4/786-O cell lines, and screened the differentially expressed genes (DEGs) in B7-H4/786-O cells by microarray analysis. The identified DEGs were subsequently validated by western blotting.

\section{Materials and methods}

Cell culture. The 786-O cell line (catalogue TCHu186) was purchased from the Shanghai Cell Bank of the Shanghai Institute for Biological Sciences. The cells were cultured in RPMI 1640 medium (Gibco, Thermo Fisher Scientific, Inc.) containing $10 \%$ fetal bovine serum (Gibco, Thermo Fisher Scientific, Inc.) at $37^{\circ} \mathrm{C}, 5 \% \mathrm{CO}_{2}$. A total of $1 \times 10^{6}$ 786-O cells/well in 24-well plates were transfected with $50 \mu \mathrm{l} /$ well LV5-B7-H4 lentivirus (Genepharma Co., Ltd) or empty vector (Genepharma Co., Ltd) with $5 \mu \mathrm{g} / \mathrm{ml}$ polybrene (Genepharma Co., Ltd) according the manufacturer's instructions. The stable expression clones were selected in medium containing $0.5 \mathrm{mg} / \mathrm{ml} \mathrm{G} 418$ (Thermo Fisher Scientific, Inc.) $24 \mathrm{~h}$ post-transfection. After 2 weeks, NC/786-O and B7-H4/786-O stable transgenic cells were obtained and subsequent experiments were performed.

To knock down B7-H4 expression in breast cancer cell line SK-BR-3, $1 \times 10^{6}$ cells were seeded in 6 -well plates $24 \mathrm{~h}$ prior to transfection. When the cells reached $70-80 \%$ confluence in each well, they were treated with Opti-MEM Reduced Serum Medium (Gibco, Thermo Fisher Scientific, Inc.) containing 50 nM B7-H4 small interfering (si)RNA (Genepharma Co., Ltd) and $10 \mu 1$ Lipofectamine ${ }^{\circledR} 2000$ (Invitrogen, Thermo Fisher Scientific, Inc.) for $6 \mathrm{~h}$. The cell supernatant was replaced with fresh medium and cells were cultured for $48 \mathrm{~h}$ prior to harvesting and subsequent experiments. The B7-H4 siRNA sequences were as follows: Forward, 5'-GCUGGAGCAAUU GCACUCAUCAUUG(dTdT)-3' and reverse, 5'-CAAUGA UGAGUGCAAUUGCUCCAGC(dTdT)-3'.

Microarray processing. For total RNA extraction, NC/786-O and B7-H4/786-O cells were harvested. Triplicate samples were prepared for each cell line. Total RNA was extracted using TRIzol reagent (Invitrogen, Thermo Fisher Scientific, Inc.) according to the manufacturer's protocol. Total RNA was quantified using a NanoDrop ND-2000 spectrophotometer (NanoDrop Technologies; Thermo Fisher Scientific, Inc.) and the RNA integrity was assessed using an Agilent Bioanalyzer
2100 (Agilent Technologies, Inc.). Total RNA was transcribed into double-stranded cDNA and labeled with cyanine-3-cytidine triphosphate. The labeled cDNAs were hybridized onto Agilent Human Gene Expression microarrays (Agilent Technologies, Inc.). The arrays were scanned by the Agilent Scanner G2505C (Agilent Technologies, Inc.). The heatmap of the gene expression in the two cell lines (triplicates of each cell line) was produced by Multiexperimental Viewer software version 4.8.1 ( $\mathrm{MeV}$ development team).

DEG analysis. Feature Extraction software version 10.7.1.1 (Agilent Technologies, Inc.) was used to analyze array images to obtain raw data. GeneSpringGX version 11.0 (Agilent Technologies) was employed for the basic analysis of the raw data, which were normalized with the quantile algorithm. Probes that had $\geq 10 \%$ values in any one of all conditions and had flags in 'Detected' were selected for further data analysis. Genes with fold-change $\geq 2$ and $\mathrm{P}<0.05$ calculated by unpaired Student's t-test between B7-H4/786-O and NC/786-O cells were identified as DEGs.

Functional enrichment analysis. To explore the functions in which DEGs were enriched in the B7-H4/786-O cell line, the identified DEGs were subjected to functional enrichment analysis with the Datasets for Annotation, Visualization and Integrated Discovery version 6.7 (david.abcc.Nicfcrf.gov). Gene Ontology (GO) (http://geneontology.org/) terms and Kyoto Encyclopedia of Genes and Genome (KEGG) pathways (https://www.kegg.jp/) with $\mathrm{P}<0.05$ were screened out.

Western blot analysis. NC/786-O and B7-H4/786-O cells were harvested and lysed in RIPA buffer. RIPA cell lysis buffer (cat. no. P0013B) was purchased from Beyotime Institute of Biotechnology. Total proteins were extracted, concentrations were determined by bicinchoninic acid assay, separated using 12\% SDS-PAGE (100 $\mu \mathrm{g} /$ lane), and the proteins were transferred onto PVDF membranes. Upon blocking in $5 \% \mathrm{BSA} / \mathrm{PBS}$ buffer at room temperature for $30 \mathrm{~min}$, the membranes were blotted with the primary antibodies at $4^{\circ} \mathrm{C}$ overnight and subsequently washed with PBS-0.05\% (v/v) Tween 20 (PBST) three times. The primary antibodies used were as follows: NME1 (1:500; cat. no. 11086-2-AP, Proteintech Group, Inc.); membrane metalloendopeptidase (MME; 1:500; cat. no 18008-1-AP; Proteintech Group, Inc.); vanin 1 (VNN1; 1:300; cat. no. 21745-1-AP; Proteintech Group, Inc.); matrix metalloproteinase 7 (MMP7; 1:300; cat. no. 10374-2-AP; Proteintech Group, Inc.); tumor necrosis factor $\alpha$ (TNF- $\alpha$; 1:2,000; cat. no. 60291-1-Ig; Proteintech Group, Inc.); human C-X-C motif chemokine ligand (CXCL) 1/2/3 (1 $\mu \mathrm{g} / \mathrm{ml}$; cat. no. MAB276; R\&D Systems, Inc.); CXCL8 (1:500; cat. no. 27095-1-AP; Proteintech Group, Inc.); human C-C motif chemokine ligand 20 (CCL20; $1 \mu \mathrm{g} / \mathrm{ml})$; cat. no. MAB360; R\&D Systems, Inc.); B7-H4 (1:500; cat. no. 12080-1-AP; Proteintech Group, Inc.); $\beta$-actin (1: 5,000; cat. no. 66009-1-Ig; Proteintech Group, Inc.) and $\alpha$-tubulin (1:2,000; cat. no. 11224-1-AP; Proteintech Group, Inc.) were used. Then, the membranes were incubated with the secondary antibodies at room temperature for $1 \mathrm{~h}$ and subsequently washed three times with PBST. The secondary antibodies horse anti-mouse IgG (H\&L)-horseradish peroxi- 
A

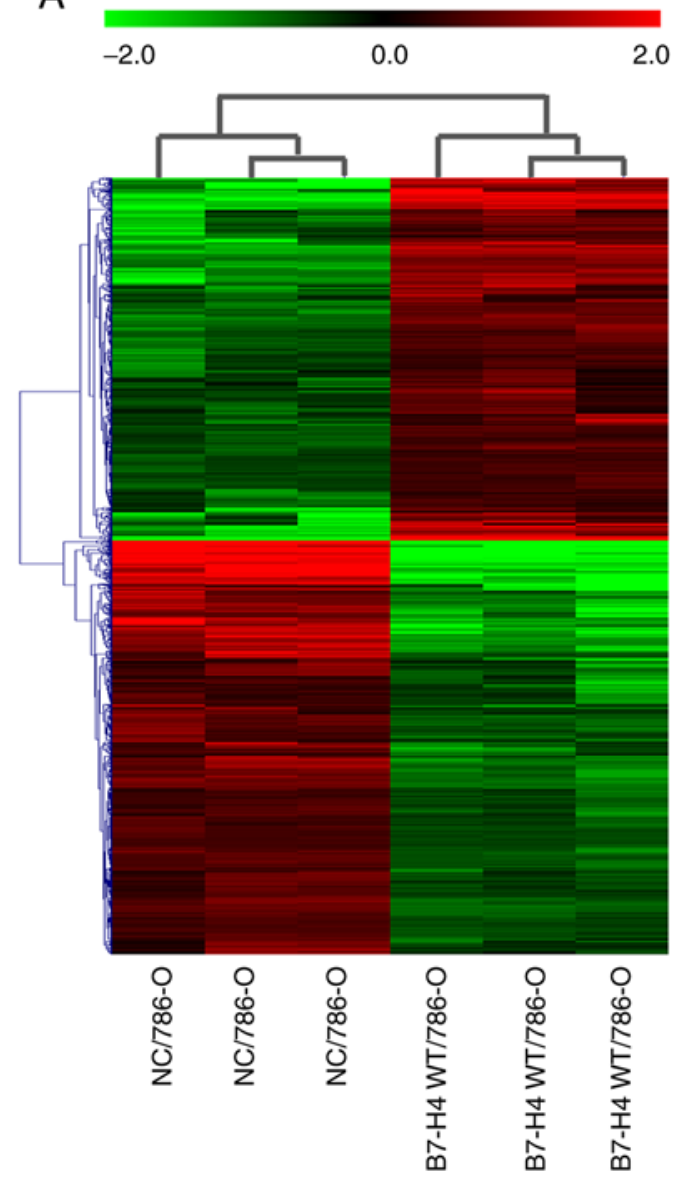

B

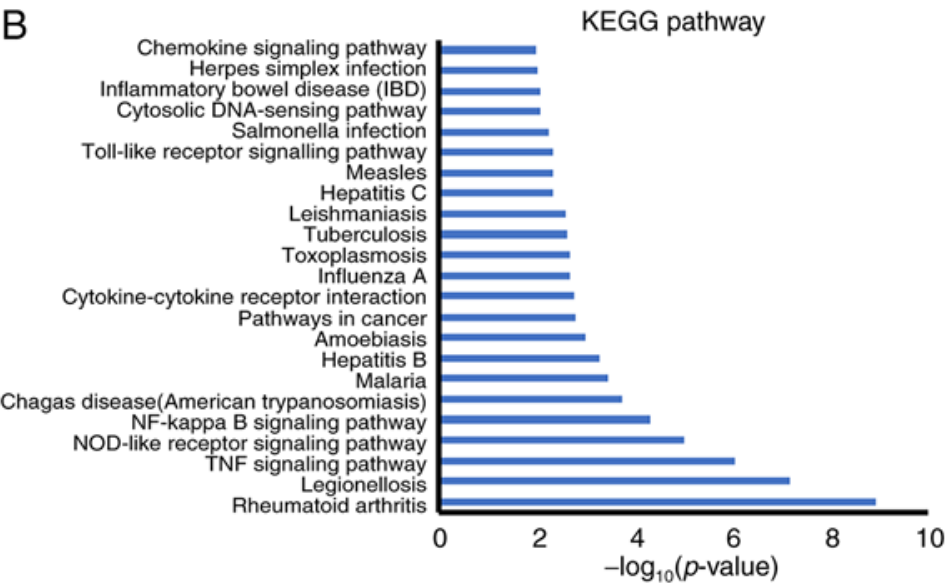

C

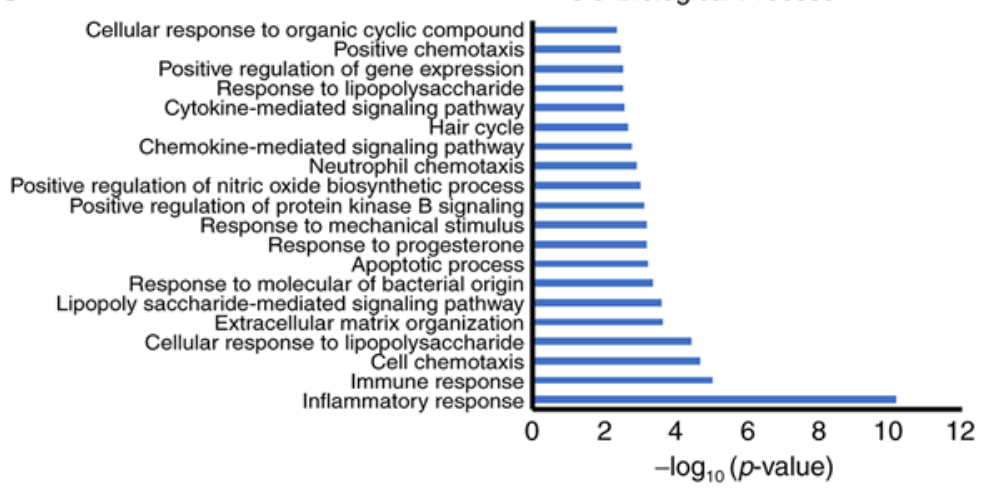

Figure 1. Identification of DEGs between NC/786-O and B7-H4/786-O cell lines by microarray analysis. (A) Heatmap of DEGs between NC/786-O and B7-H4/786-O cells. (Red, upregulated genes; green, downregulated genes and black, unchanged genes). (B) Significant KEGG signaling pathways (P $\leq 0.01$ ) of the upregulated genes are shown. No significant KEGG pathway was identified for the downregulated genes. (C) GO terms enrichment analysis of BPs. The top 20 BPs are shown. DEGs, differential expressed genes; NC, negative control; B7-H4, B7 family member, H4; KEGG, Kyoto Encyclopedia of Genes and Genomes; BP, biological process; GO, Gene Ontology; WT, wild-type.

dase (HRP; 1:1,000; cat. no. 7076;) and goat anti-rabbit IgG (H\&L)-HRP (1:1,000; cat. no. 7074) were purchased from Cell Signaling Technology, Inc. The membranes were immersed in ECL detection reagent and imaged with a Gel Doc ${ }^{\mathrm{TM}} \mathrm{EZ}$ system (Bio-Rad Laboratories, Inc.). $\beta$-actin or $\alpha$-tubulin were used as loading controls. The intensities of the bands were determined by Image Lab software version 4.1 (Bio-Rad Laboratories, Inc.). Three independent experiments were performed.

The Cancer Genome Atlas (TCGA) analysis. RNA-sequencing TCGA data were analysed using the Gene Expression Profiling Interactive Analysis (GEPIA) website (gepia. cancer-pku.cn/index.html), which is an interactive web server for analysing RNA-sequencing expression data from TCGA and Genotype-Tissue Expression databases (24). The correlation between B7-H4 and the expression of chemokine genes CXCL1, CXCL2, CXCL3, CXCL8 and CCL20 was evaluated by the Pearson's correlation test. $\mathrm{P}<0.05$ was considered to indicate a statistically significant difference.

Immunohistochemistry (IHC). The use of clinical samples was approved by the Soochow University Ethical Review Board, and written informed consent was obtained from the patients.
A total of 59 specimens fixed with $10 \%$ formalin at room temperature for $24 \mathrm{~h}$ and embedded in paraffin were collected from the Second Affiliated Hospital of Soochow University were used for IHC analysis. The patients included 36 males and 23 females (mean age, 59 years; age range 39-78 years). All patients had a pathological diagnosis of renal cell carcinoma and underwent radical nephrectomy. Sections $(4-\mu \mathrm{m})$ were deparaffinized in serial grades of xylene followed by rehydration in sequentially increasing dilutions of ethanol. Upon antigen retrieval was performed by saline sodium citrate (microwave heating for $30 \mathrm{~min}$ ), endogenous peroxidase was blocked by $3.0 \%$ hydrogen peroxide at room temperature for $1 \mathrm{~h}$. Non-specific interactions were blocked using $1.5 \%$ blocking serum (Dako, Agilent Technologies, Inc.) in PBS for $10 \mathrm{~min}$ at room temperature. Then the sections were incubated with primary antibodies against B7-H4 (1:100; cat. no. 12080-1-AP; Proteintech Group, Inc.); CCL20 (1:200; cat. no. 26572-1-AP; Proteintech Group, Inc.) and CXCL8 (1:200; cat. no. 27095-1-AP; Proteintech Group, Inc.) at $4^{\circ} \mathrm{C}$ overnight. The sections were then incubated with a HRP-conjugated goat anti-rabbit secondary antibody (1:50; cat. no. GK600705; Gene Tech Co., Ltd.) at room temperature for $1 \mathrm{~h}$. Then the sections were stained by the avidin-biotin immunoperoxidase method. For negative control staining, the primary antibodies 
Table I. Upregulated differentially expressed genes involved in the inflammatory response, immune response and cell chemotaxis.

\begin{tabular}{lcccc}
\hline $\begin{array}{l}\text { Gene } \\
\text { symbol }\end{array}$ & $\begin{array}{c}\text { Regulation } \\
\text { (BW/NC) }\end{array}$ & $\begin{array}{c}\text { FC } \\
\text { (BW/NC) }\end{array}$ & $\begin{array}{c}\text { Regulation } \\
\text { (BW/BM) }\end{array}$ & $\begin{array}{c}\text { FC } \\
\text { (BW/BM) }\end{array}$ \\
\hline IL33 & $\mathrm{Up}$ & 379.026787 & $\mathrm{Up}$ & 258.11453 \\
TLR2 & $\mathrm{Up}$ & 34.398422 & $\mathrm{Up}$ & 2.3269036 \\
CXCL1 & $\mathrm{Up}$ & 34.114403 & $\mathrm{Up}$ & 104.74504 \\
CXCL8 & $\mathrm{Up}$ & 29.291115 & $\mathrm{Up}$ & 125.44275 \\
CSF2 & $\mathrm{Up}$ & 27.370817 & $\mathrm{Up}$ & 142.67291 \\
CCL20 & $\mathrm{Up}$ & 17.881693 & $\mathrm{Up}$ & 26.53977 \\
CXCL2 & $\mathrm{Up}$ & 15.134712 & $\mathrm{Up}$ & 29.041739 \\
TNF & $\mathrm{Up}$ & 11.655401 & $\mathrm{Up}$ & 14.347787 \\
NME5 & $\mathrm{Up}$ & 11.342079 & $\mathrm{Up}$ & 7.7392936 \\
VNN1 & $\mathrm{Up}$ & 10.856487 & $\mathrm{Up}$ & 10.219795 \\
IGF2 & $\mathrm{Up}$ & 10.503797 & $\mathrm{Up}$ & 7.646981 \\
MMP7 & $\mathrm{Up}$ & 10.202435 & $\mathrm{Up}$ & 3.5069153 \\
CXCL3 & $\mathrm{Up}$ & 9.860397 & $\mathrm{Up}$ & 24.532923 \\
PTGS2 & $\mathrm{Up}$ & 9.696702 & $\mathrm{Up}$ & 3.1078327 \\
MMP1 & $\mathrm{Up}$ & 8.226387 & $\mathrm{Up}$ & 12.556886 \\
CCL2 & $\mathrm{Up}$ & 5.6037107 & $\mathrm{Up}$ & 10.624764 \\
CXCL5 & $\mathrm{Up}$ & 4.761648 & $\mathrm{Up}$ & 5.3687253 \\
MME & $\mathrm{Up}$ & 3.3166819 & $\mathrm{Up}$ & 5.5750117 \\
\hline
\end{tabular}

BW, B7-H4 wild-type/786-O; NC, negative control/786-O; FC, fold-change; BM, B7-H4 nuclear localization sequence mutant/786-O; B7-H4, B7 family member, H4; up, upregulated.

were omitted in the procedure. The sections were observed under a light microscope (CX43; Olympus Corporation) at x400 magnification and evaluated and graded independently by two investigators. The Allred scoring system was used (25). The signal intensity was graded from 0 to $3(0$, none; 1 , weak; 2 , intermediate; and 3, strong), and the percentage of positive tumor cells was scored according to a scale from 1 to $5(1,<1$; $2,1-10 ; 3,10-30 ; 4,30-60$; and 5, $>60 \%)$. An Allred score of $\mathrm{B} 7-\mathrm{H} 4<80$ was designated as $\mathrm{B} 7-\mathrm{H} 4^{\text {low }}$, while $>80$ was designated as $\mathrm{B} 7-\mathrm{H} 4^{\text {high }}$.

Mouse and tumor models. Non-obese diabetic/severe combined immunodeficiency mice (age, 4 weeks; male) were purchased from Joinn Laboratories (China), Co., Ltd. Mice were kept in pathogen-free facilities under conventional conditions with controlled temperature $\left(22 \pm 2^{\circ} \mathrm{C}\right)$ and humidity $(55 \pm 10 \%)$ and 12 -h dark/light cycles. The mice were allowed free access to food and water. All animal experiments were approved and conducted in compliance with institutional guidelines established by the Ethics Committee of Soochow University (Suzhou, China). Mice were subcutaneously inoculated into the left axilla with $5 \times 10^{6} 786-\mathrm{O}$ transfected cells suspended in serum-free PBS. Mice were intraperitoneally injected with isotype IgG or anti-CXCL8 antibody once every 3 days at a dose of $1 \mathrm{mg} / \mathrm{kg}$ ( $\mathrm{n}=6$ mice/group). Tumor growth was assessed twice a week. The orthogonal tumor dimensions were measured with a calliper. The tumor volume was calculated according to the formula $\mathrm{V}=\mathrm{a} \times \mathrm{b}^{2} / 2$, where $\mathrm{V}$ is the volume, $\mathrm{a}$ is the maximum diameter and $\mathrm{b}$ is the smallest diameter. When the tumor diameter reached $20 \mathrm{~mm}$ or tumor volume reached $1,500 \mathrm{~mm}^{3}$, the mice were preemptively euthanized by cervical dislocation and the tumor tissues were isolated and weighed. During the present study, the maximum body weight loss is in a mouse due to cachexia was $9.8 \%$, and the longest diameter exhibited by a single subcutaneous tumor was $1.8 \mathrm{~cm}$. No mice exhibited multiple tumors.

Flow cytometry. Flow cytometry analysis of tumor infiltrated neutrophils in tumor tissues was performed as described previously (26). Tumor tissues were mechanically dissected into small pieces and further digested with a mixture of Liberase ${ }^{\mathrm{TM}}$ TL (Roche Applied Science) and DNase. Cells digested from the tumor tissues were filtered through a 70- $\mu \mathrm{m}$ filter, fixed with $4 \%$ paraformaldehyde at room temperature for $15 \mathrm{~min}$, and incubated in PBS containing 1\% FBS (cat. no. 10099141; Gibco, Thermo Fisher Scientific, Inc.) and 3 mM EDTA at room temperature for $20 \mathrm{~min}$ to block non-specific binding. The cells were incubated with an anti-mouse cluster of differentiation (CD) $16 / 32$ antibody $\left(2.5 \mu \mathrm{g} / 10^{6}\right.$ cells; cat. no. MAB1460; R\&D Systems, Inc.) at $4^{\circ} \mathrm{C}$ for $30 \mathrm{~min}$. Cells were stained with fluorescein isothiocyanate-conjugated CD45 $\left(0.25 \mu \mathrm{g} / 10^{6}\right.$ cells; cat. no. 147709, Biolegend, Inc.); P-phycoerythrin-conjugated CD11b $\left(0.25 \mu \mathrm{g} / 10^{6}\right.$ cells; cat. no. 101207; Biolegend, Inc.) and APC-conjugated lymphocyte antigen 6 complex, locus $\mathrm{G}$ antibodies $\left(0.06 \mu \mathrm{g} / 10^{6}\right.$ cells; cat. no. 127613 ; Biolegend, Inc.) at $4^{\circ} \mathrm{C}$ for $30 \mathrm{~min}$. Flow cytometry data acquisition was performed on a BD FACSCalibur (BD Biosciences) and analysed by FlowJo version 7.6 (BD Biosciences).

Statistical analysis. . All data are expressed as the mean \pm SD from at least triplicate experiments. For the correlation analysis between B7-H4 and upregulated DEGs in TCGA data, the Pearson's correlation test was used. For the chemokine IHC score, the unpaired Student's t-test was used to evaluate the difference in two groups (dichotomized according B7-H4 level). For multiple groups in the mouse model, quantitative data was analysed by the one-way ANOVA. Multiple comparisons among the groups were performed using the Tukey's post hoc test. SPSS 19.0 software (IBM Corp.) was used for all statistical analysis. $\mathrm{P}<0.05$ was considered to indicate a statistically significant difference.

\section{Results}

Identification of DEGs in microarray datasets and functional enrichment analysis. To identify the effects of B7-H4 overexpression on the function of renal cell carcinoma cells, the total mRNA extracted from NC/786-O and B7-H4/786-O cells was subjected to microarray analysis. The heatmap of the gene expression in the two cell lines (triplicates of each cell line) is presented in Fig. 1A. In total, 724 upregulated and 804 downregulated DEGs were obtained. The significantly enriched KEGG pathways of upregulated genes in the B7-H4/786-O cell line were analyzed. The KEGG pathways of upregulated genes with $\mathrm{P} \leq 0.01$ are shown in Fig. 1B. The results revealed that there was a significant association with 'rheumatoid arthritis', 


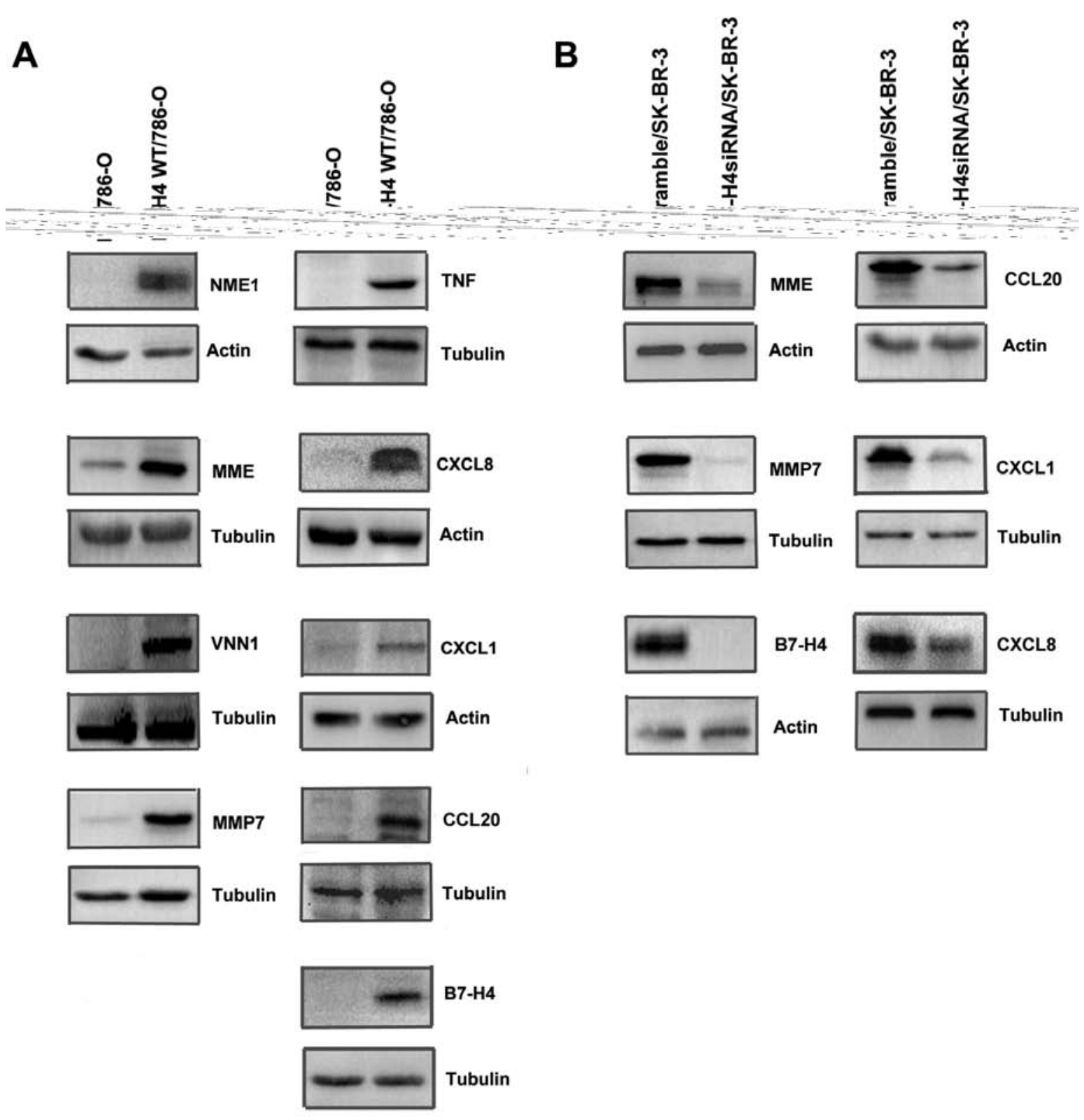

Figure 2. Verification of the upregulated differentially expressed genes induced by B7-H4 expression in 786-O and SK-BR-3 cell lines. Western blot analysis was performed on the total protein extracted from (A) negative control/786-O and B7-H4/786-O cell lines and (B) scramble siRNA/SK-BR-3 and B7-H4 siRNA/SK-BR-3 cell lines. B7-H4, B7 family member, H4; siRNA, small interfering. As many proteins were examined, tubulin or actin were used as loading control for each protein depending on how to cut the PVDF membrane. In pre-experiments, we found that the expression level of tubulin was strictly parallel to actin in each cell line. So both of them could be used as loading control freely for each cell line.

'legionellosis', 'TNF signaling pathway', 'nucleotide-binding oligomerization domain (NOD)-like receptor signaling pathway', 'NF-кB signaling pathway' and 'chemokine signaling pathway' (Fig. 1B). GO terms enrichment analysis for upregulated DEGs was performed. The top 20 biological processes (BPs) are presented in Fig. 1C. The results revealed that 'inflammatory response', 'immune response', 'cell chemotaxis' and 'cellular response to lipopolysaccharide' were associated with the upregulated DEGs (Fig. 1C).

Verification of upregulated DEGs by B7-H4 via western blotting. By GO BP analysis, the predominant BPs of the upregulated DEGs were 'inflammatory response', 'immune response' and 'cell chemotaxis', all of which are associated with the immune characteristics of tumor cells. Further analysis of GO revealed that IL33, TLR2, CXCL1 and CXCL8 were involved in these BPs. The upregulated DEGs involved in these BPs are listed in Table I. Next, the protein level of upregulated DEGs in 786-O transfectants was verified using western blot analysis. Fig. 2A revealed that the protein levels of NME1, MME, VNN1, MMP7, TNF, CXCL8, CXCL1 and CCL20 were upregulated in B7-H4/786-O cells compared with NC/786-O cells. To further confirm the effect of B7-H4 on the expression of these cytokines, the SK-BR-3 cell line was transfected with scramble small interfering (si)RNA and B7-H4 siRNA. Western blot analysis demonstrated that loss of B7-H4 in the SK-BR-3 cell line resulted in decreased MME, MMP7, CXCL8, CXCL1 and CCL20 (Fig. 2B). Both 
A
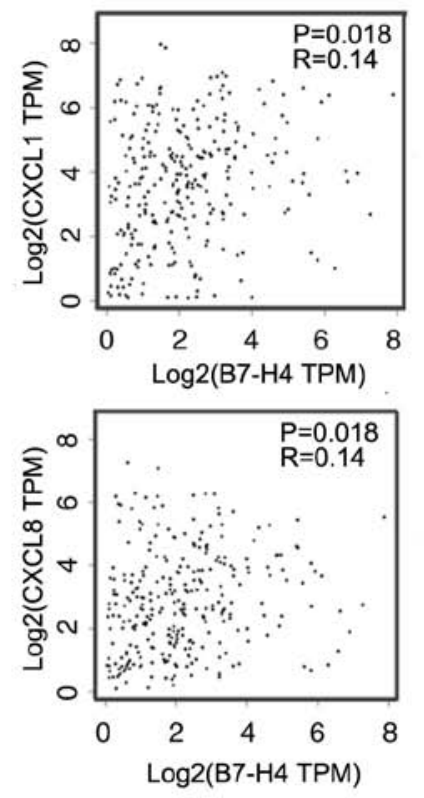

B
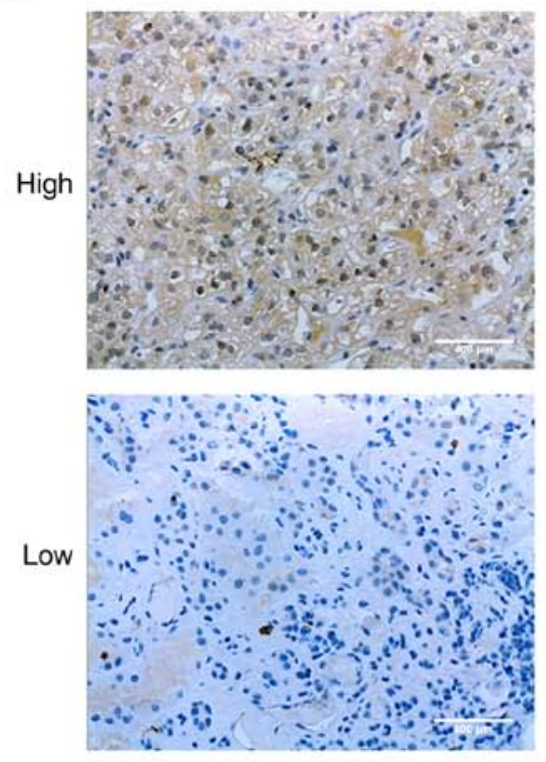

Kidney renal papillary cell carcinoma (KIRP)
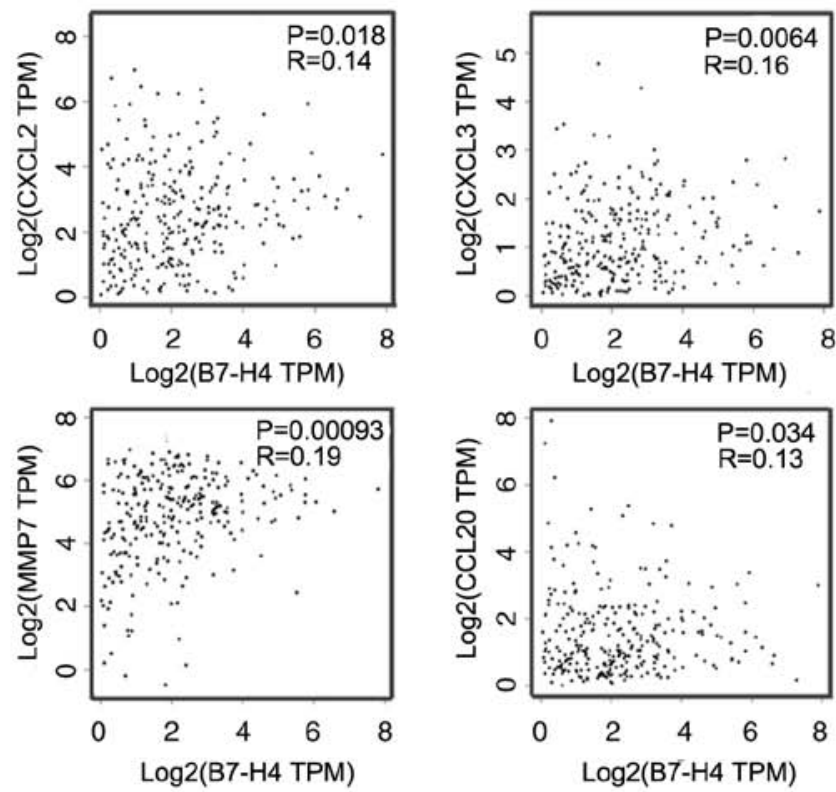

C

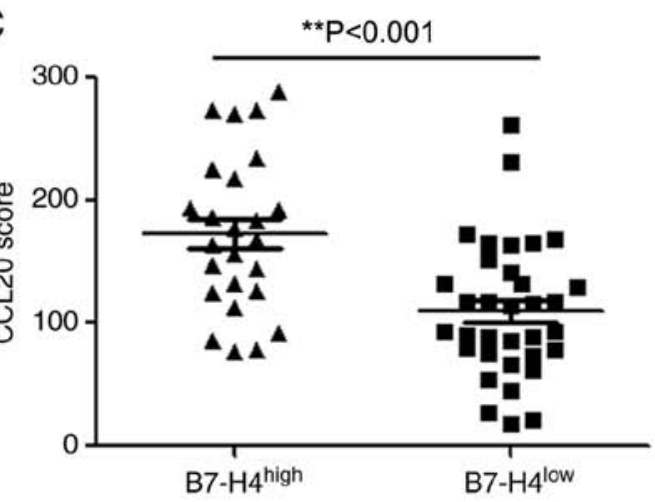

CCL20
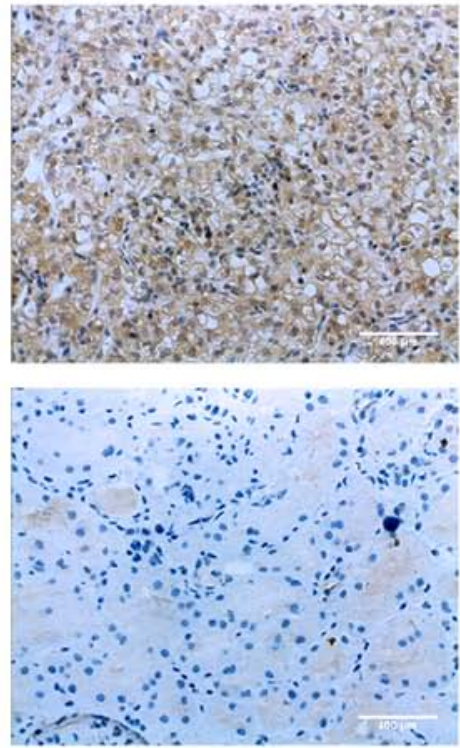

CXCL8
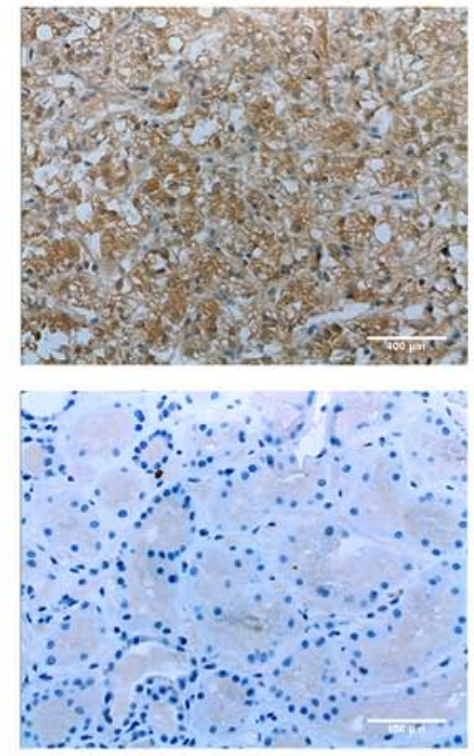

${ }^{* *} \mathrm{P}<0.001$

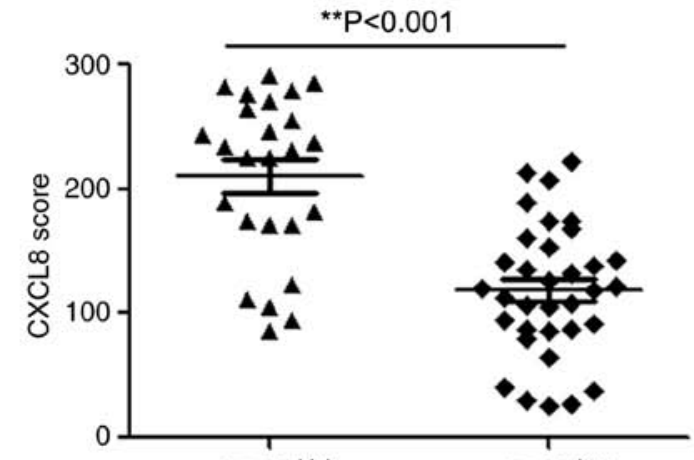

B7- $4^{\text {high }}$

B7- $4^{\text {low }}$

Figure 3. Association of B7-H4 with the differentially expressed genes is confirmed in clinical renal cell carcinoma tissues and TCGA datasets. (A) RNA-sequencing data of TCGA data analysed using the Gene Expression Profiling Interactive Analysis website. The correlation of B7-H4 gene in kidney renal papillary cell carcinoma was analysed using the Pearson's correlation test. (B) Immunohistochemical analysis of B7-H4, CCL20 and CXCL8 in clinical renal cell carcinoma tissues. Representative images are shown. Magnification x400. Scale bar, $400 \mu \mathrm{m}$. (C) Statistical analysis of the CCL20 and CXCL8 levels in B7-H4 ${ }^{\text {high }}$ and B7-H4 $4^{\text {low }}$ tissues using the Student's t-test. ${ }^{\text {*** }}$ P $<0.01$. B7-H4, B7 family member, H4; TCGA, The Cancer Genome Atlas; CCL20, C-C motif chemokine ligand 20; CXCL8, C-X-C motif chemokine ligand. 
Table II. Patient characteristics.

\begin{tabular}{|c|c|c|c|}
\hline \multirow{2}{*}{$\begin{array}{l}\text { Clinical } \\
\text { variable }\end{array}$} & \multicolumn{2}{|c|}{ B7-H4 level } & \multirow[b]{2}{*}{$\mathrm{P}$-value } \\
\hline & B7-H4 ${ }^{\text {high }}(n=25)$ & $\mathrm{B} 7-\mathrm{H} 4^{\text {low }}(\mathrm{n}=34)$ & \\
\hline $\begin{array}{l}\text { Age, years } \\
(\text { mean } \pm S D)\end{array}$ & $57.6 \pm 9.8$ & $60.3 \pm 8.3$ & 0.267 \\
\hline$<60$ & 14 & 14 & 0.260 \\
\hline$\geq 60$ & 11 & 20 & \\
\hline Sex & & & 0.891 \\
\hline Male & 15 & 21 & \\
\hline Female & 10 & 13 & \\
\hline Grade & & & 0.010 \\
\hline G1-2 & 16 & 31 & \\
\hline G3-4 & 9 & 3 & \\
\hline T stage & & & 0.200 \\
\hline $\mathrm{T} 1-2$ & 17 & 28 & \\
\hline T3-4 & 8 & 6 & \\
\hline
\end{tabular}

a Statistical analysis using the Pearson chi-square test. B7-H4, B7 family member, $\mathrm{H} 4$; T, tumor.

overexpression and knocking down of B7-H4 in cancer cell lines confirmed that B7-H4 expression led to upregulation of the cytokines that were identified by microarray analysis.

TCGA and IHC analyses reveal the upregulation of chemokines by B7-H4 in clinical renal carcinoma. To further confirm the upregulation of cytokines by B7-H4 in cancer cell lines, the present study analyzed chemokine gene expression in clinical kidney tumors. The RNA-sequencing data of TCGA were analysed using the GEPIA website (10). As presented in Fig. 3A, B7-H4 mRNA was associated with increased CXCL1, CXCL2, CXCL3, CXCL8, MMP7 and CCL20 mRNA levels in renal papillary cell carcinoma. Although the correlations were not strong according to the $\mathrm{R}$ values, they were significant. These data further verified the results obtained in the cell lines. A total of 59 clinical renal carcinoma tissues were collected, and B7-H4, CXCL8 and CCL20 expression was evaluated by IHC staining. The patient characteristics are shown in Table II. B7-H4 high expression was associated with tumor grade. As shown in Fig. 3B, representative specimens with high B7-H4 expression exhibited high levels of CCL20 and CXCL8, while specimens with low B7-H4 expression exhibited low levels of CCL20 and CXCL8. There was a positive association between CCL20 and CXCL8 levels with B7-H4 (Fig. 3C). These data suggested that B7-H4 expression enhanced CCL20 and CXCL8 levels in clinical renal carcinoma.

B7-H4 promotes tumor proliferation and infiltrating neutrophils by upregulating CXCL8. Since CXCL8 promoted tumor progression by recruiting tumor-associated neutrophils (27), the present study investigated the role of CXCL8 in the tumor promotion role of B7-H4. NC/786-O and B7-H4/786-O cell lines were inoculated into mice, and isotype $\operatorname{IgG}$ or anti-CXCL8 antibody were administered. The tumor growth curve is shown in Fig. 4A. After 21 days, tumor tissues were isolated and the tumor weight was evaluated. Fig. 4B revealed that overexpression of B7-H4 significantly promoted tumor growth when isotype IgG was administered. However, when administering anti-CXCL8 antibody, there was no difference between NC/786-O and B7-H4/786-O, suggesting that B7-H4 promoted tumor growth through CXCL8. The fold-change in B7-H4/786-O (isotype/anti-CXCL8) decreased more significantly than in $\mathrm{NC} / 786-\mathrm{O}$ (Fig. 4C). The gating strategy of tumor-infiltrating $\mathrm{CD} 11 \mathrm{~b}^{+} \mathrm{Ly}_{6 \mathrm{G}}{ }^{+}$neutrophils was shown in Fig. 4D. The results demonstrated that, in the isotype IgG-treated group, the ratio of infiltrating neutrophils in B7-H4/786-O was significantly higher than in $\mathrm{NC} / 786-\mathrm{O}$ (Fig. 4E and F), but in the anti-CXCL8-treated group, no difference in the number of infiltrated neutrophils existed between the two cell lines. This result suggested that overexpressed B7-H4 in tumors induced neutrophil recruitment through CXCL8.

\section{Discussion}

B7-H4 is an important negative co-stimulatory molecule of the B7 family $(8,9,17)$. B7-H4 protein expression is restricted to activated T cells, B cells, DCs and macrophages (8). Additionally, it has been reported that B7-H4 is upregulated in several types of cancer (28-31), which suggests that B7-H4 has the potential to be used as a biomarker or therapeutic target for tumors (19,31-33). However, other studies revealed that B7-H4 promotes cell proliferation $(34,35)$, invasion and metastasis of tumor cells $(15,35,36)$, enhances leukemia-initiating cell differentiation (23), and is correlated with carcinogenesis and chemoresistance $(34,37)$.

There are multiple mechanisms by which B7-H4 can affect tumor cell biology. Wang et al (34) reported that silencing B7-H4 enhances drug-induced apoptosis by inhibiting the phosphatase and tensin homolog (PTEN)/PI3K/AKT signaling pathway, indicating the role of B7-H4 in chemoresistance and suggesting that it may be an attractive therapeutic target in triple-negative breast cancer. Xie et al (15) demonstrated that B7-H4 induced epithelial-mesenchymal transition, and promoted invasion and metastasis of tumor cells by the activation of the ERK1/2 signaling pathway. Furthermore, upregulated B7-H4 expression was associated with downregulated Bax, upregulated Bcl-2 and activation of caspase-3 (15). Qian et al (38) analyzed the microRNA (miRNA) expression profile following B7-H4 knockdown in pancreatic cancer cell line L3.6p1 and noticed that the differentially expressed miRNAs induced by B7-H4 siRNA were mainly involved in the mitogen-activated protein kinase and PI3K/AKT signaling pathways. Chen et al (37) demonstrated that B7-H4 expression is positively correlated with IL6 expression and signal transducer and activator of transcription 3 phosphorylation. Xia et al (23) revealed that B7-H4 is one of the highly expressed immune molecules on human acute myeloid leukemia cells, and promotes the differentiation of leukemia-initiating cells through the PTEN/AKT/hypoxia-inducible factor-1 $\alpha / \mathrm{REST}$ corepressor $2 /$ runt-related transcription factor 1 signaling pathway (23).

The present study constructed B7-H4 wild-type overexpressing cells to investigate the specific DEGs induced by 
A

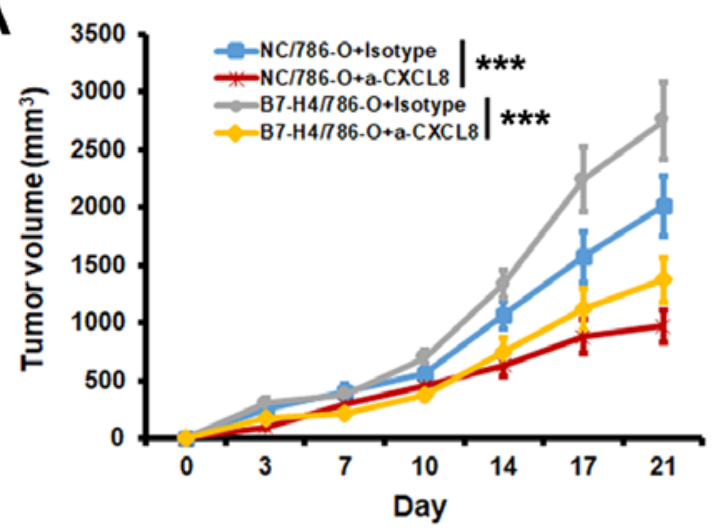

B

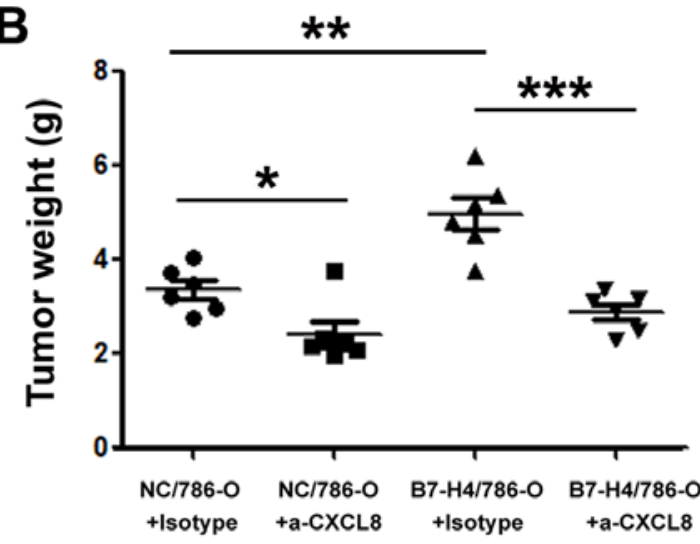

C
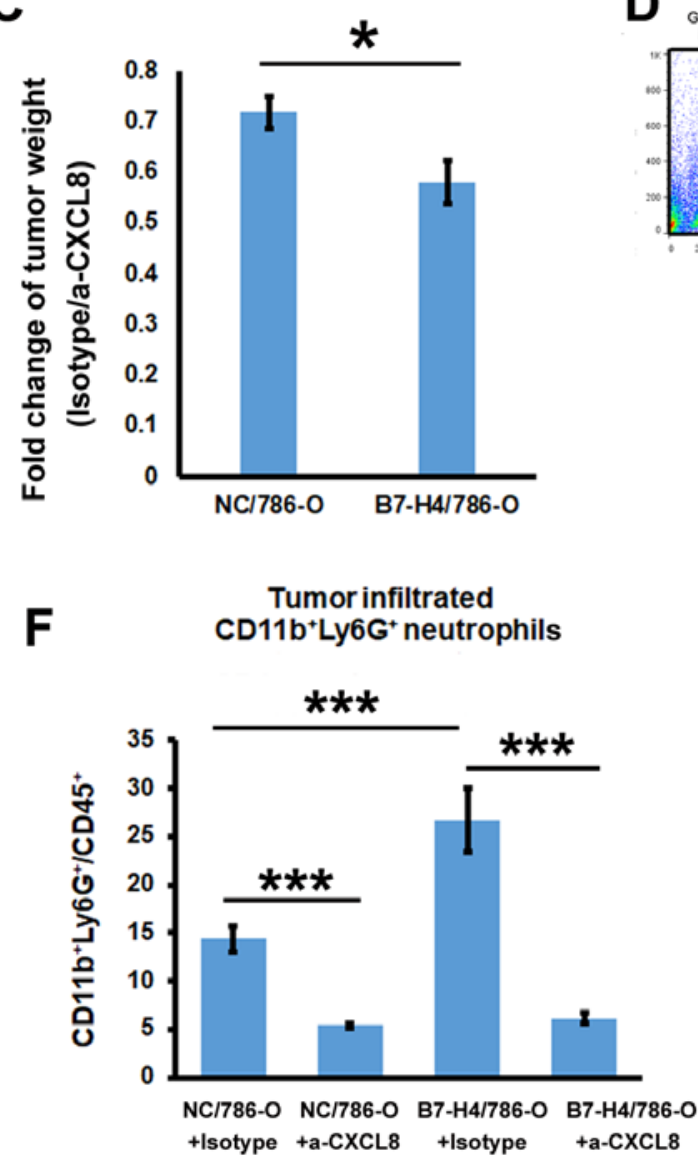

Dated on neutrophils
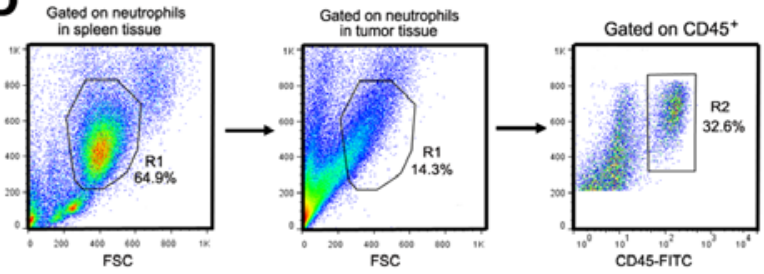

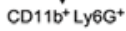

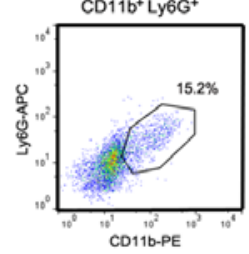

$\mathbf{E}$
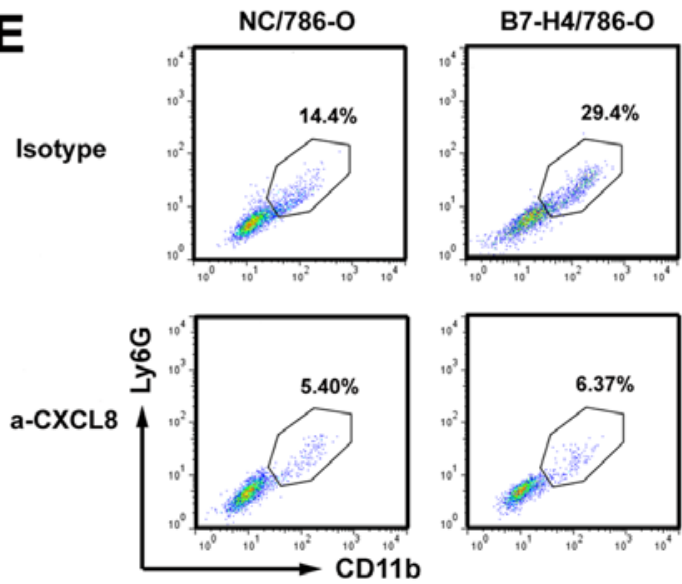

Figure 4. Evaluation of the effects of CXCL8 on the B7-H4-mediated promotion of tumor growth and tumor-infiltrating neutrophils. 786-O transfectants were inoculated into non-obese diabetic/severe combined immunodeficiency mice (n=6/group). (A) Tumor growth curve was evaluated by assessing tumor volume. The tumor volumes on day 21 showed significance, ${ }^{* * *} \mathrm{P}<0.001$. (B) Tumor weight was evaluated after 21 days of treatment with isotype IgG or anti-CXCL8 antibody $(n=6)$. (C) Fold-change of tumor weight between the isotype IgG and anti-CXCL8 antibody groups. (D) Gating strategy of CD11b ${ }^{+}$Ly6G ${ }^{+}$in tumor tissues is shown. (E) Tumor-infiltrating neutrophils were analysed by flow cytometry. Cells from tumor tissues were stained with fluorescein conjugated CD45, $\mathrm{CD} 11 \mathrm{~b}$ and $\mathrm{Ly} 6 \mathrm{G}$. The ratio of $\mathrm{CD} 11 \mathrm{~b}^{+} \mathrm{Ly}_{6 \mathrm{G}}{ }^{+}$in $\mathrm{CD} 45^{+}$cells was evaluated by flow cytometry. (F) Statistical analysis of the ratio $\mathrm{CD} 11 \mathrm{~b}^{+} \mathrm{Ly} 6 \mathrm{G}^{+} / \mathrm{CD} 45^{+}(\mathrm{n}=6)$. Multiple comparisons among the groups were performed using the Tukey's post hoc test. ${ }^{*} \mathrm{P}<0.05,{ }^{* * *} \mathrm{P}<0.01,{ }^{* * *} \mathrm{P}<0.001$, as indicated. CXCL8, C-X-C motif chemokine ligand; B7-H4, B7 family member, H4; CD, cluster of differentiation; Ly6G, lymphocyte antigen 6 complex, locus G.

B7-H4 wild-type in 786-O cells. The results revealed that there were 704 upregulated and 804 downregulated DEGs. The upregulated DEGs were associated with the inflammatory response, immune response and cell chemotaxis. Of the upregulated DEGs obtained by microarray, the upregulation of NME, MME, VNN1, MMP7, TNF, CXCL8, CXCL1 and
CCL20 were confirmed by western blot analysis. Since all these molecules are involved in the inflammatory response, immune response and cell chemotaxis, the current study further examined the chemokine expression in clinical renal carcinoma by TCGA dataset analysis and IHC staining in 59 clinical tumor tissues. The results revealed that there was a 
positive correlation between B7-H4 and CCL20 or CXCL8. Furthermore, B7-H4 increased tumor-associated infiltrating neutrophils by upregulating CXCL8, indicating another mechanism in the tumor promoting effect of B7-H4. Similar the results obtained in the present study, Azuma et al (39) revealed a correlation between serum B7-H4 and neutrophil in peripheral blood from the patients with clear cell renal cancer. The present study demonstrated that B7-H4 expression increased tumor-infiltrating neutrophils by upregulating CXCL8 and that blocking CXCL8 reversed this increase. The present study revealed the molecular mechanism underlying the B7-H4-associated increase in tumor-infiltrating neutrophils, and suggested that B7-H4 and CXCL8 might serve as therapeutic targets to remodel the tumor microenvironment.

Besides CXCL8, the chemokine CCL20 is also upregulated in B7-H4-transfected cells. CCL20 is an 8-kDa protein involved in the maintenance of immunological homeostasis (40). $\mathrm{T}$ cells, natural killer (NK) cells, B cells and immature DCs are recruited to the tumor by the interaction of CCL20 with CCR6 (41-43). As CCL20 recruits both anti-tumor leukocytes and pro-tumor leukocytes (regulatory T cells, myeloid dendritic cells and NK cells), the role of CCL20 in tumor progression is complex (44). Tumor cells, macrophages and neutrophils produce CXCL1 and recruit myeloid-derived suppressor cells, which suppress the activity of $\mathrm{CD} 8^{+} \mathrm{T}$ effector cells to prevent tumor cell killing by $\mathrm{CD}^{+} \mathrm{T}$ cells $(44,45)$. Thus, upregulated CXCL1 expression by B7-H4 expression may contribute to tumor progression (44). Of the upregulated DEGs identified in the present study, MMP7 exhibited the largest fold-change difference. MMPs are a family of enzymes responsible for the degradation of a wide spectrum of extracellular matrix and non-matrix proteins (46). During carcinogenesis, MMPs can regulate the microenvironment and contribute to several critical steps in cancer development via their involvement in cell proliferation, differentiation, apoptosis, invasion, migration and immune surveillance (46-48). Thus, upregulated MMP7 expression by B7-H4 may serve an important role in tumor progression.

In conclusion, the results of the present study revealed that in renal cell carcinoma, B7-H4 may upregulate CXCL1, CXCL8, CCL20 and MMP7 and thus recruit tumor-associated neutrophils.

\section{Acknowledgements}

The authors would like to thank Dr Chuanyang Sun (The Department of Urology, The Second Affiliated Hospital of Soochow University, Suzhou, China) for his valuable assistance in collecting clinical samples.

\section{Funding}

The present study was supported by the National Nature Science Foundation of China (grant nos. 31370872, 81402381 and 81502454).

\section{Availability of data and materials}

The datasets used and/or analyzed during the present study are available from the corresponding author on reasonable request.

\section{Authors' contributions}

LZ designed the study wrote the manuscript. AL performed the cellular experiments. NZ performed the experiments on the clinical samples. ZZ performed the bioinformatics and statistical analyses. AL and YC performed the animal experiments. All authors read and approved the final manuscript.

\section{Ethics approval and consent to participate}

The present study was approved and guided by the Ethics Committee of Soochow University (Suzhou, China). All patients provided written informed consent.

\section{Patient consent for publication}

Not applicable.

\section{Competing interests}

The authors declare that they have no competing interests.

\section{References}

1. Ferlay J, Soerjomataram I, Dikshit R, Eser S, Mathers C, Rebelo M, Parkin DM, Forman D and Bray F: Cancer incidence and mortality worldwide: Sources, methods and major patterns in GLOBOCAN 2012. Int J Cancer 136: E359-E386, 2015.

2. Rooney MS, Shukla SA, Wu CJ, Getz G and Hacohen N: Molecular and genetic properties of tumors associated with local immune cytolytic activity. Cell 160: 48-61, 2015.

3. Santoni M, Berardi R, Amantini C, Burattini L, Santini D, Santoni G and Cascinu S: Role of natural and adaptive immunity in renal cell carcinoma response to VEGFR-TKIs and mTOR inhibitor. Int J Cancer 134: 2772-2777, 2014.

4. Motzer RJ, Hutson TE, Tomczak P, Michaelson MD, Bukowski RM, Rixe O, Oudard S, Negrier S, Szczylik C, Kim ST, et al: Sunitinib versus interferon alfa in metastatic renal-cell carcinoma. N Engl J Med 356: 115-124, 2007.

5. Motzer RJ, Escudier B, McDermott DF, George S, Hammers HJ, Srinivas S, Tykodi SS, Sosman JA, Procopio G, Plimack ER, et al: Nivolumab versus everolimus in advanced renal-cell carcinoma. N Engl J Med 373: 1803-1813, 2015.

6. Gill DM, Hahn AW, Hale P and Maughan BL: Overview of current and future first-line systemic therapy for metastatic clear cell renal cell carcinoma. Curr Treat Options Oncol 19: 6, 2018.

7. Kawashima A, Uemura $M$ and Nonomura N: Importance of multiparametric evaluation of immune-related T-cell markers in renal-cell carcinoma. Clin Genitourin Cancer 17: e1147-e1152, 2019.

8. Sica GL, Choi IH, Zhu G, Tamada K, Wang SD, Tamura H, Chapoval AI, Flies DB, Bajorath J and Chen L: B7-H4, a molecule of the B7 family, negatively regulates $\mathrm{T}$ cell immunity. Immunity 18: 849-861, 2003.

9. Zang X, Loke P, Kim J, Murphy K, Waitz R and Allison JP: B7x: A widely expressed B7 family member that inhibits T cell activation. Proc Natl Acad Sci USA 100: 10388-10392, 2003.

10. Tang Z, Li C, Kang B, Gao G, Li C and Zhang Z: GEPIA: A web server for cancer and normal gene expression profiling and interactive analyses. Nucleic Acids Res 45: W98-W102, 2017.

11. Li C, Zhan Y, Ma X, Fang H and Gai X: B7-H4 facilitates proliferation and metastasis of colorectal carcinoma cell through PI3K/Akt/mTOR signaling pathway. Clin Exp Med: Oct 29, 2019 doi: 10.1007/s10238-019-00590-7 (Epub ahead of print).

12. Genova C, Boccardo S, Mora M, Rijavec E, Biello F, Rossi G, Tagliamento M, Dal Bello MG, Coco S, Alama A, et al: Correlation between B7-H4 and survival of non-small-cell lung cancer patients treated with nivolumab. J Clin Med 8: pii: E1566, 2019.

13. Gruosso T, Gigoux M, Manem VSK, Bertos N, Zuo D, Perlitch I, Saleh SMI, Zhao H, Souleimanova M, Johnson RM, et al: Spatially distinct tumor immune microenvironments stratify triple-negative breast cancers. J Clin Invest 129: 1785-1800, 2019. 
14. Krambeck AE, Thompson RH, Dong H, Lohse CM, Park ES, Kuntz SM, Leibovich BC, Blute ML, Cheville JC, Kwon ED, et al: B7-H4 expression in renal cell carcinoma and tumor vasculature: Associations with cancer progression and survival. Proc Natl Acad Sci USA 103: 10391-10396, 2006.

15. Xie N, Cai JB, Zhang L, Zhang PF, Shen YH, Yang X, Lu JC, Gao DM, Kang Q, Liu LX, et al: Upregulation of B7-H4 promotes tumor progression of intrahepatic cholangiocarcinoma. Cell Death Dis 8: 3205, 2017.

16. Zhu J, Chu BF, Yang YP, Zhang SL, Zhuang M, Lu WJ and Liu YB: B7-H4 expression is associated with cancer progression and predicts patient survival in human thyroid cancer. Asian Pac J Cancer Prev 14: 3011-3015, 2013.

17. Prasad DV, Richards S, Mai XM and Dong C: B7S1, a novel $\mathrm{B} 7$ family member that negatively regulates $\mathrm{T}$ cell activation. Immunity 18: 863-873, 2003 .

18. Li J, Lee Y, Li Y, Jiang Y, Lu H, Zang W, Zhao X, Liu L, Chen Y, Tan H, et al: Co-inhibitory molecule B7 superfamily member 1 expressed by tumor-infiltrating myeloid cells induces dysfunction of Anti-tumor CD8(+) T cells. Immunity 48: 773-786.e5, 2018.

19. Chen C, Qu QX, Xie F, Zhu WD, Zhu YH and Huang JA: Analysis of B7-H4 expression in metastatic pleural adenocarcinoma and therapeutic potential of its antagonists. BMC Cancer 17: 652, 2017.

20. Chen C, Zhu WD, Xie F and Huang JA: Nuclear localization of B7-H4 in pulmonary adenocarcinomas presenting as a solitary pulmonary nodule. Oncotarget 7: 58563-58568, 2016.

21. Zhang L, Wu H, Lu D, Li G, Sun C, Song H, Li J, Zhai T, Huang L, Hou C, et al: The costimulatory molecule B7-H4 promote tumor progression and cell proliferation through translocating into nucleus. Oncogene 32: 5347-5358, 2013.

22. Jeon YK, Park SG, Choi IW, Lee SW, Lee SM and Choi I: Cancer cell-associated cytoplasmic B7-H4 is induced by hypoxia through hypoxia-inducible factor-1a and promotes cancer cell proliferation. Biochem Biophys Res Commun 459: 277-283, 2015.

23. Xia F, Zhang Y, Xie L, Jiang H, Zeng H, Chen C, Liu L, He X, Hao X, Fang X, et al: B7-H4 enhances the differentiation of murine leukemia-initiating cells via the PTEN/AKT/RCOR2/RUNX1 pathways. Leukemia 31: 2260-2264, 2017.

24. Tang Z, Li C, Kang B, Gao G and Zhang Z: GEPIA: A web server for cancer and normal gene expression profiling and interactive analyses. Nucleic Acids Res 45: W98-W102, 2017.

25. Allred DC, Clark GM, Elledge R, Fuqua SA, Brown RW Chamness GC, Osborne CK and McGuire WL: Association of p53 protein expression with tumor cell proliferation rate and clinical outcome in node-negative breast cancer. J Natl Cancer Inst 85: 200-206, 1993.

26. Wang DH, Lee HS, Yoon D, Berry G, Wheeler TM, Sugarbaker DJ, Kheradmand F, Engleman E and Burt BM Progression of EGFR-Mutant lung adenocarcinoma is driven by alveolar macrophages. Clin Cancer Res 23: 778-788, 2017.

27. Ogawa R, Yamamoto T, Hirai H, Hanada K, Kiyasu Y, Nishikawa G, Mizuno R, Inamoto S, Itatani Y, Sakai Y and Kawada K: Loss of SMAD4 promotes colorectal cancer progression by recruiting tumor-associated neutrophils via CXCL1/8-CXCR2 axis. Clin Cancer Res 25: 2287-2899, 2019.

28. Wang L, Heng X, Lu Y, Cai Z, Yi Q and Che F: Could B7-H4 serve as a target to activate anti-cancer immunity? Int Immunopharmacol 38: 97-103, 2016.

29. Bregar A, Deshpande A, Grange C, Zi T, Stall J, Hirsch H, Reeves J, Sathyanarayanan S, Growdon WB and Rueda BR: Characterization of immune regulatory molecules B7-H4 and PD-L1 in low and high grade endometrial tumors. Gynecol Oncol 145: 446-452, 2017.

30. Han S, Wang Y, Shi X, Zong L, Liu L, Zhang J, Qian Q, Jin J, Ma Y, Cui B, et al: Negative roles of B7-H3 and B7-H4 in the microenvironment of cervical cancer. Exp Cell Res 371: 222-230, 2018.
31. Huang $\mathrm{H}, \mathrm{Li} \mathrm{C}$ and Ren G: Clinical significance of the B7-H4 as a novel prognostic marker in breast cancer. Gene 623: 24-28, 2017.

32. MacGregor HL and Ohashi PS: Molecular pathways: Evaluating the potential for B7-H4 as an immunoregulatory target. Clin Cancer Res 23: 2934-2941, 2017.

33. Tan Z and Shen W: Prognostic role of B7-H4 in patients with non-small cell lung cancer: A meta-analysis. Oncotarget 8: 27137-27144, 2017.

34. Wang L, Yang C, Liu XB, Wang L and Kang FB: B7-H4 overexpression contributes to poor prognosis and drug-resistance in triple-negative breast cancer. Cancer Cell Int 18: 100, 2018.

35. Qian Y, Sang Y, Wang FX, Hong B, Wang Q, Zhou X, Weng T, Wu Z, Zheng M, Zhang $\mathrm{H}$ and Yao $\mathrm{H}$ : Prognostic significance of B7-H4 expression in matched primary pancreatic cancer and liver metastases. Oncotarget 7: 72242-72249, 2016

36. Han S, Li Y, Zhang J, Liu L, Chen Q, Qian Q, Li S and Zhang Y: Roles of immune inhibitory molecule B7-H4 in cervical cancer. Oncology Rep 37: 2308-2316, 2017.

37. Chen X, Wang W, Man H, Li P and Shan B: Increased B7-H4 expression during esophageal squamous cell carcinogenesis is associated with IL-6/STAT3 signaling pathway activation in mice. Oncol Lett 13: 2207-2215, 2017.

38. Qian Y, Feng L, Wu W, Weng T, Hu C, Hong B, Wang FXC, Shen L, Wang Q, Jin X and Yao H: MicroRNA expression profiling of pancreatic cancer cell line L3.6p1 following B7-H4 Knockdown. Cell Physiol Biochem 44: 494-504, 2017.

39. Azuma T, Sato Y, Ohno T, Azuma M and Kume H: Serum soluble B7-H4 is a prognostic marker for patients with non-metastatic clear cell renal cell carcinoma. PLoS One 13: e0199719, 2018.

40. Jacquelot N, Duong CPM, Belz GT and Zitvogel L: Targeting chemokines and chemokine receptors in melanoma and other cancers. Front Immunol 9: 2480, 2018.

41. Zhang Y, Roth TL, Gray EE, Chen H, Rodda LB, Liang Y, Ventura P, Villeda S, Crocker PR and Cyster JG: Migratory and adhesive cues controlling innate-like lymphocyte surveillance of the pathogen-exposed surface of the lymph node. Elife 5: pii: e18156, 2016.

42. Ramirez-Valle F, Gray EE and Cyster JG: Inflammation induces dermal $\mathrm{V} \gamma 4+\gamma \delta \mathrm{T} 17$ memory-like cells that travel to distant skin and accelerate secondary IL-17-driven responses. Proc Natl Acad Sci USA 112: 8046-8051, 2015.

43. Hartwig T, Pantelyushin S, Croxford AL, Kulig P and Becher B: Dermal IL-17-producing $\gamma \delta$ T cells establish long-lived memory in the skin. Eur J Immunol 45: 3022-3033, 2015.

44. Vilgelm AE and Richmond A: Chemokines modulate immune surveillance in tumorigenesis, metastasis, and response to immunotherapy. Front Immunol 10: 333, 2019.

45. Susek KH, Karvouni M, Alici E and Lundqvist A: The role of CXC chemokine receptors 1-4 on immune cells in the tumor microenvironment. Front Immunol 9: 2159, 2018.

46. Young D, Das N, Anowai A and Dufour A: Matrix metalloproteases as influencers of the Cells' social media. Int J Mol Sci 20: pii: E3847, 2019.

47. Liao CH, Chang WS, Hu PS, Wu HC, Hsu SW, Liu YF, Liu SP, Hung HS, Bau DT and Tsai CW: The Contribution of MMP-7 promoter polymorphisms in renal cell carcinoma. In Vivo 31: 631-635, 2017.

48. Zhang Z, Dong T, Fu Y, Zhou W, Tian X, Chen G and Liu S: MMP-11 promotes papillary thyroid cell proliferation and invasion via the NF-кB pathway. J Cell Biochem: Sep 1, 2018 doi: 10.1002/jcb.27500 (Epub ahead of print).

This work is licensed under a Creative Commons Attribution-NonCommercial-NoDerivatives 4.0 International (CC BY-NC-ND 4.0) License. 